\title{
Witnessing Bullying at Work: Inactivity and the Risk of Becoming the Next Target
}

Michael Rosander and Morten B. Nielsen

The self-archived postprint version of this journal article is available at Linköping University Institutional Repository (DiVA):

http://urn.kb.se/resolve?urn=urn:nbn:se:liu:diva-182068

N.B.: When citing this work, cite the original publication.

Rosander, M., Nielsen, M. B., (2021), Witnessing Bullying at Work: Inactivity and the Risk of Becoming the Next Target, Psychology of Violence. https://doi.org/10.1037/viooooo406

Original publication available at:

https://doi.org/10.1037/vio0000406

Copyright: American Psychological Association

http://www.apa.org/ 


\title{
Witnessing Bullying at Work Inactivity and the Risk of Becoming the Next Target
}

\author{
Michael Rosander ${ }^{* 1} \&$ Morten B. Nielsen ${ }^{2,3}$ \\ ${ }^{I}$ Department of Behavioural Sciences and Learning, Linköping University, Linköping, Sweden \\ ${ }^{2}$ National Institute of Occupational Health, Oslo, Norway \\ ${ }^{3}$ Department of psychosocial science, University of Bergen, Bergen, Norway
}

\begin{abstract}
Objective

Bullying is a form of psychological violence defined as a prolonged, systematic mistreatment at work where the victim has difficulties defending themself. While the antecedents and consequences for those exposed to workplace bullying are well known, little is known about the consequences for bystanders who intervene when witnessing bullying of others. To fill this knowledge gap, this study examines the risk of bystanders becoming the next target of workplace bullying if they intervene or remain inactive.

Method

The study is based on a longitudinal probability sample of the Swedish workforce $(\mathrm{n}=$ 788). To assess new victims of bullying, respondents bullied at baseline were excluded from the analyses. The analyses were adjusted for sex, age, place of birth, education, employment period at the current place of work, managerial position, mental health problems and unclear roles in the organization.
\end{abstract}

\section{Results}

The results showed no increased risk of becoming a new victim of bullying for respondents who had actively intervened when witnessing bullying of others. In contrast, respondents who remained inactive had a threefold risk of becoming a victim of bullying at follow-up.

\section{Conclusions}

The findings point to the importance of intervening when witnessing bullying, both for the victim and for oneself, and that this may help the organization become a safer workplace.

Keywords: workplace violence, aggression, mistreatment, bystander, intervening

Workplace bullying is a form of psychological violence responsible for much suffering on an individual level (Mikkelsen et al., 2020), as well as for a reduction in productivity and effectivity at the organizational level (Hoel et al., 2020). Bullying is defined as a prolonged, systematic mistreatment at work where the victim has difficulties defending themself(Einarsen et al., 2020). In addition to being detrimental for those exposed, recent evidence suggests that bullying also has significant ripple effects for bystanders in that witnessing bullying of others influences the work-related attitudes of the witnesses, and even their mental health (Nielsen et al., 2021; Salin \& Notelaers, 2020). Nielsen et al. (2021) found that about one-third of employees at some point the had witnessed bullying at the workplace during the past six-month period. Consequently, a pending question is how witnesses can reduce the potential harm to both oneself and those targeted. Theoretically, the answer is quite simple; one can either try to intervene to stop it, or one can be inactive and let the bullying continue. Both options have

\footnotetext{
* Correspondence concerning this article should be addressed to Michael Rosander, Department of Behavioural Sciences and Learning, Linköping University, Campus Valla, 58183 Linköping, Sweden. Email: michael.rosander@liu.se
} 
potential benefits and risks. By intervening one can help the target and contribute to ending the bullying. On the other hand, one of the common reasons for not intervening when witnessing bullying at work is the fear of becoming the next target (Baez-Leon et al., 2016; D'Cruz \& Noronha, 2011). However, despite this relatively straight-forward dichotomy regarding what to do when witnessing bullying, to our knowledge no studies have investigated the actual consequences of intervening against workplace bullying. Therefore, the overarching aim of this exploratory study was to examine risks associated with witnessing bullying at work. What are the risks of being bullied oneself if one intervenes or if one remains inactive in such a situation?

\section{Bystanding to Workplace Bullying}

The current study only focus on the two broad bystander behaviours - intervening or not when witnessing bullying. However, theoretically, there are a number of ways to act as a bystander, and there are a number of bystander roles (see e.g., Linstead, 2013; Paull et al., 2012). Paull et al. (2012) described active, passive, destructive, and constructive bystander roles. Active and constructive roles involve helping the victim, whereas an active and destructive role is to join the bully and thereby facilitating and worsening the situation. Passive roles can be to try to avoid the situation or the victim, or silently empathize with the victim. The way one acts is highly dependent on the relation to the target (D'Cruz \& Noronha, 2011) and one's status or power in relation to the perpetrator (Lutgen-Sandvik \& McDermott, 2011).

An important question is what makes a person intervene or decide to remain inactive. According to the model of third parties' responses by O'Reilly and Aquino (2011), to some extent based on the deontic model of justice (Cropanzano et al., 2003), thoughts of justice and moral anger may lead a witness to act. Niven et al. (2020) presented a process model of bystander responses to workplace bullying. According to this model, witnessing an incident of potential bullying initiates cognitive appraisal in terms of, for example, the severity of the incident. The cognitive appraisal is influenced by several personal and situational factors, such as categorization processes, and identification with the victim and/or the perpetrator. This leads to an emotional reaction (e.g., anger, sympathy, or schadenfreude). Influenced by personal factors, such as one's perceived power, and situational factors, such as the organizational climate the outcome is some form of behavioural response - be it active or passive, destructive or constructive (cf. Paull et al., 2012).

There are also other possible processes in play when deciding to act or not. Hellemans et al. (2017) studied attribution processes and found support for a negative effect of internal attributions and a positive effect of external attributions - for both public support and emotional support. This means that whether one frames the situation as something that can be blamed on the victim or caused by other factors external to the victim, contribute to the decision about what to do. Ng et al. (2019) presented a model of bystander behaviours in terms of sensemaking processes. As bullying behaviour can be indirect and ambiguous, witnessing bullying of others is likely to encourage subjective interpretations to understand what is happening. These interpretations involve, for example, appraisal of severity, and whether the victim is perceived to deserve the treatment. The model also includes post-hoc sensemaking which could have an effect on future bullying incidents one becomes a witness to ( $\mathrm{Ng}$ et al., 2019).

Alternatively, one can reverse the question - why not intervene? One way of thinking about this is the bystander effect (Latané \& Darley, 1970). It describes several preconditions, that is, requirements for a witness to act. First, one must become aware of the situation. For a bystander it may not be obvious that a particular act is in fact bullying, because many possible bullying behaviours may be ambiguous and indirect in nature. Next, one needs to interpret the situation as something serious - critical enough to intervene. If there are other witnesses, their reaction may contribute to the interpretation. Finally, one needs to feel responsible, and feel 
confident that there is a chance of succeeding if intervening. There are a number of cognitive processes that may influence this latter condition: diffusion of responsibility (the more bystanders the less chance of acting), evaluation of apprehension (fear of having interpreted the situation incorrectly and acting on that in a public setting), and pluralistic ignorance (when interpreting the seriousness of a situation based on how others are reacting to the situation). Niven et al. (2020) argued that a bullying situation is different than the situations described by Latané and Darley (1970) as they were based on non-recurring events. To a victim, bullying is certainly recurring, but to a bystander it is not certain that the systematic nature of the mistreatment is known, nor is it obvious that all negative behaviours are interpreted as bullying as some may be ambiguous and indirect. Meta-analytic findings suggest that non-emergencies, that is, situation without obvious immediate danger, were associated with a larger bystander effect than emergencies (Fischer et al., 2011). So, the processes behind the bystander effect may be of value when trying to understand bystander behaviours also in the context of workplace bullying.

Fear of retaliation may also influence the likelihood of intervening when witnessing bullying of others (Baez-Leon et al., 2016; D'Cruz \& Noronha, 2011). Research on whistleblowing, that is, organizational members who speak out about perceived wrongdoings at the workplace, show that employees who report illegal, immoral, or illegitimate practices in their organization have a higher risk of being bullied when compared to non-whistleblowers (Bjørkelo, 2013; Bjørkelo et al., 2011). It should be noted that the study by Bjørkelo and colleagues used cross-sectional data, so the causal relations in this regard are unclear. Whistleblowing is described as a process that builds up over time and often involve higher order organizational problems and formal power structures, however, it may also be actions that harm individual employees (Bjørkelo et al., 2011; Latan et al., 2019). The immediate reactions and actions when witnessing bullying would probably not be regarded as blowing the whistle per se. Nevertheless, if an employee knows that when people previously have raised their voices against wrongdoings it has led to some sort of retaliation for the whistleblower, this may reduce the likelihood of acting when witnessing bullying.

\section{Goals of the Current Study}

Taken together, the above discussion indicates that bystanders have reasons to both intervene and not intervene when perceiving bullying of others. However, much is unknown regarding the consequences of the behaviours witnesses to bullying at work can have. The current study is therefore exploratory and addresses these consequences in terms of risks associated with the decision to intervene or not. As presented above, the fear of becoming the next target is an important reason for inaction as a witness (Baez-Leon et al., 2016; D'Cruz \& Noronha, 2011). To determine whether intervening when witnessing bullying leads to an increased risk of becoming exposed oneself, we answer the following research questions:

1. What is the risk of being bullied at a later timepoint if witnessing bullying at baseline (without being bullied oneself) and intervening compared to all others not bullied at baseline?

2. What is the risk of being bullied at a later timepoint if witnessing bullying at baseline (without being bullied oneself) and not intervening compared to all others not bullied at baseline?

Previous research on risk factors of workplace bullying have shown an increased risk of bullying in organizations lacking in role clarity (Salin \& Hoel, 2020), and for employees with mental health problems (Nielsen et al., 2014). Although not entirely clear, many studies have shown that women are more exposed to bullying than men (Zapf et al., 2020). Age is controlled for in many studies, but there are indications of a higher risk of bullying for younger 
employees (Lewis et al., 2011). Being born abroad is a clear risk factor (Rosander \& Blomberg, 2021). Managerial position may influence the risk of bullying as bullying per definition involves a power imbalance (Einarsen et al., 2020), and Salin (2001) found less bullying in higher levels of an organization. Due to their associations with workplace bullying, the abovementioned factors were considered as necessary control with regard to answering the research questions.

\section{Methods}

\section{Participants}

The data used in the study was a probability sample of the whole Swedish workforce (3.3 million employees) working at workplaces with ten or more employees (ages 18-65 years). The baseline in the study was collected in the autumn of 2017 and the follow-up in the spring of 2019. In Figure 1 the data, drop-outs, exclusions, and groupings are presented. With data from both waves collected we excluded participants based on two criteria. To be included in the analyses they needed to have stayed at the same workplace for both data collections. People who have changed jobs are not exposed to the possible risks of intervening when witnessing bullying at the workplace at baseline. They could be bullied at follow-up, but the reason would be something else. The other exclusion criterion involves being bullied at baseline. As we wanted to study possible effects of intervening, being bullied oneself at baseline makes the association to subsequent bullying unclear. After applying these exclusion criteria 788 respondents were included in the analyses - of those, 101 had witnessed bullying at baseline and intervened, and 111 had witnessed bullying at baseline but had not intervened.

\section{Figure 1}

The Data Set, Drop-Outs, Excluded Data, and Groupings

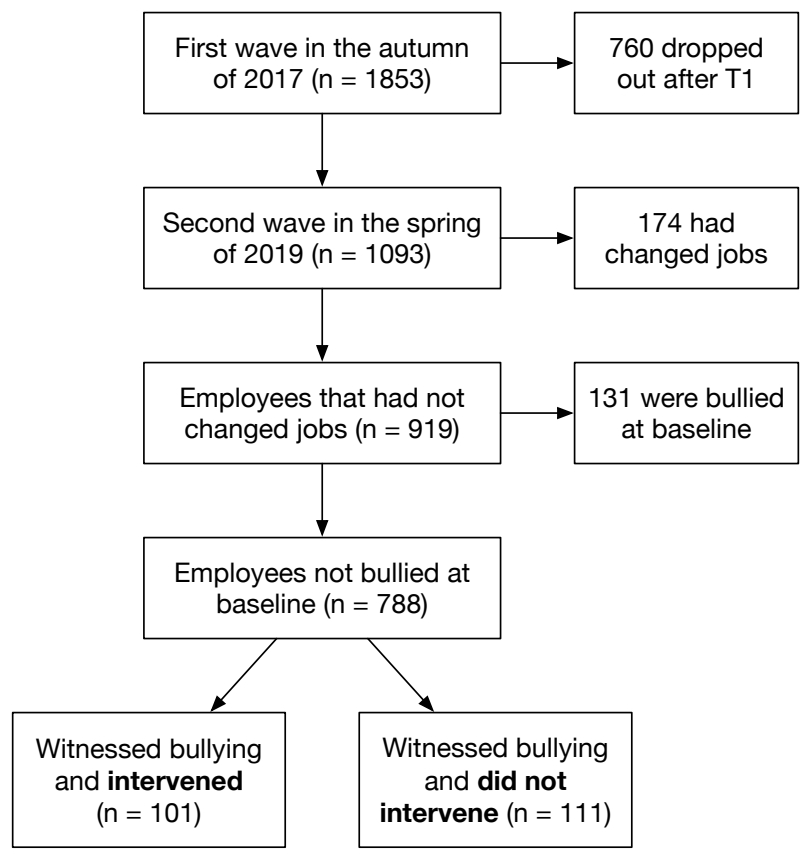

Answers from 788 participants were used in the study. There were 59\% women and $41 \%$ men, $91 \%$ were born in Sweden (2\% were born in another Nordic country, $5 \%$ were born in the rest of Europe, and 2\% were born outside Europe), and 14\% had a managerial position. The mean age was 50.3 years $(\mathrm{SD}=9.8)$. The participants had worked at their current workplace for 14.5 years $(\mathrm{SD}=12.0)$. A majority had at least some university or college education 
$(60 \%)$; one third (35\%) had $10-12$ years of education while the rest $(5 \%)$ had 9 years or less. All demographic information, except seniority at the current workplace, were taken directly from the Swedish national population registry. Consequently, regarding gender, this study is limited to data on biological sex.

\section{Procedures}

An invitation to take part in the study was sent out by Statistics Sweden in September 2017. Statistics Sweden is the Swedish government agency, operating under the Ministry of Finance, that is responsible for producing official statistics for decision-making, debate and research. Statistics Sweden was responsible for all aspects regarding sampling procedures, implementation and quality assurance. The data collection was open until November the same year. Those who answered the baseline questionnaire were invited to take part in the followup which started in March 2019 and ended in May 2019. For each data collection the participants received information about the study for an informed consent to participate. To ensure anonymity, in both data collections we, the researchers, were not informed about names, addresses or other identifying information - this was all handled by Statistics Sweden. Once the data collections ended, Statistics Sweden added demographic information to the data taken directly from the Swedish population register. This meant, for example, that the variable sex used in the current study is biological sex as that is what is registered in the population register. When the demographic information was added the data was sent to us.

\section{Measures}

\section{Workplace Bullying}

Workplace bullying was measured using the Negative Acts Questionnaire-Revised (NAQ-R, Einarsen et al., 2009). The NAQ-R measures 22 bullying behaviours ranging from work-related bullying to person-related bullying and intimidating behaviours. Answers are given on a five-point frequency scale from never (1) to daily (5). The internal consistency (Cronbach's alpha) for the NAQ-R was .89 at baseline and .82 at follow-up. The NAQ-R is a valid instrument with which to study workplace bullying (Einarsen et al., 2009; Notelaers \& Einarsen, 2013). Einarsen et al. (2009) used a confirmatory approach together with a latent class cluster analysis as well as investigating the associations to other relevant measures such as health, job satisfaction, and commitment to scrutinize the validity of the NAQ-R. In the study we categorize the scores based on a cut-off score suggested by Notelaers and Einarsen (2013). To use an appropriate cut-off is important as exposure to a few infrequent bullying behaviours does not make it bullying. For example, if a person gets their opinions ignored or gets humiliated in connection to work only now and then over the past six months and nothing else it is not an example of bullying. Being bullied requires a systematic mistreatment. The cutoff scores suggested by Notelaers and Einarsen (2013) take that into account. They used a ROC-analysis (receiver operation characteristics) aiming to find a balance between sensitivity and specificity to find an appropriate cut-off. One is categorized as bullied if having a sum score of 33 or higher on the NAQ-R, and not bullied if having a score below 33. Being categorized as bullied using the cut-off can occur if a target is exposed to many different negative acts over time, each one not necessarily very frequently, or a few negative acts very frequently.

\section{Bystander Behaviours}

The bystander behaviour was measured, first by establishing that the person was a witness to bullying: "Have you witnessed someone being exposed to at least some of the abovementioned negative acts during the past 6 months at your workplace?" (following directly after the NAQ-R). The answers were given on the same frequency scale as the NAQ-R. If the 
respondents reported being a witness to bullying at least now and then a question about intervening followed: "If you have witnessed someone being exposed to negative acts at your workplace, have you tried to intervene?" $(\mathrm{Yes} / \mathrm{No})$. This means we only measure whether a witness tried to intervene to help the victim or not - not the many possible bystander roles that have been described in the literature. To only investigate new cases of bullying at follow-up, all who were bullied at baseline $(\mathrm{n}=131)$, that is, if having an NAQ-R sum score on or above 33 at baseline, were excluded from further analyses. The variable Intervened includes all who witnessed bullying at baseline and intervened $(\mathrm{n}=101)$, compared to all others not bullied at baseline $(\mathrm{n}=687)$. The variable Did not intervene includes all who witnessed bullying at baseline but did not intervene $(\mathrm{n}=111)$, compared to all others not bullied at baseline $(\mathrm{n}=$ 677).

\section{Mental Health Problems}

Mental health problems were measured using the Hospital Anxiety and Depression Scale (HADS, Zigmond \& Snaith, 1983). The HADS comprises 14 items and a response scale with four alternatives (0-3), for example, "I feel cheerful" with possible responses from "Not at all" to "Most of the time". The internal consistency for the HADS at baseline was .88 . The HADS was used as a control variable in the study. The validity of the HADS has been examined in many studies (see e.g., Bjelland et al., 2002; Cosco et al., 2012).

\section{Unclear Roles in the Organization}

Roles in the organization (RIM) was measured using a scale from the Psychosocial Work Environment Questionnaire (PSYWEQ, Rosander \& Blomberg, 2018). RIM is based on six items focussing on: (a) unclear roles, responsibilities and tasks; (b) a clear division of tasks; (c) clear roles; (d) an orderly organization; (e) well-functioning routines and organization; and (f) clear role expectations. The response scale for the RIM is a seven-point Likert scale. The internal consistency in the current sample at baseline was .88. High values mean clear roles. The RIM was used as a control variable in the study. Its psychometric properties have been explored (Rosander \& Blomberg, 2018), and associations to other relevant measures have been established (Rosander, 2021; Rosander \& Blomberg, 2019).

\section{Covariates}

In the analyses we controlled for a number of demographic variables: sex, age, place of birth, and education. As regards work, we also controlled for employment period at the current place of work, and for managerial position. Also, we adjusted for two important risk factors for workplace bullying: mental health problems (Nielsen et al., 2014) and unclear roles in the organization (Salin \& Hoel, 2020). All covariates were measured at baseline.

\section{Data Analysis Plan}

The analyses were conducted using IBM SPSS version 27. We used logistic regression to investigate the risks associated with intervening and with inaction when witnessing bullying. First, the crude odds ratios (OR) for all study variables were calculated, then one analysis for each of the two conditions, action or inaction, were conducted including the covariates. Odds ratio is an index of the effect size. According to Chen et al. (2010) Cohen's d $<0.2$ corresponds to $\mathrm{OR}<1.5$, and Cohen's $\mathrm{d}>0.8$ corresponds to $\mathrm{OR}>5$.

As this study is a part of a larger questionnaire survey that assessed multiple variables, a power analysis relating to the research questions was not conducted prior to the data collection. Although we acknowledge that the actual usefulness of retrospective power analyses has been a topic of discussion (Zhang et al., 2019), we conducted a post hoc analyses in G*Power (Erdfelder et al., 1996) that included the association between intervening and risk of becoming 
a victim of bullying displayed in Table 2. The power to detect an OR of 1.6 with a p-value of .05 was determined to be .99986 . The power to detect an OR of 3.62 with a p-value of .05 was 1.00 .

\section{Results}

Table 1 presents the descriptive statistics and intercorrelations of all study variables. There were 302 participants who reported being a witness to bullying at baseline $(33 \%$ of all who answered both waves and had not changed jobs). Of these, 212 had not been bullied themselves, that is, $27 \%$ of those not bullied at baseline witnessed bullying, and of these 111 $(52 \%)$ remained inactive when witnessing bullying and $101(48 \%)$ intervened. Comparing those who witnessed bullying to those who did not showed no significant differences for any of the background variables used in the study. Those who witnessed bullying worked at workplaces with less clear roles $(\mathrm{RIM}), t(786)=5.57, p<.001$. This is expected, as the clarity of roles is a known risk factor for bullying. They also had a higher level of mental health problems (HADS), $t(782)=-4.81, p<.001$. Comparing those who intervened to those who did not intervene showed no significant differences for any of the background or control variables used in the study.

Table 1

Descriptive Statistics and Intercorrelations for the Study Variables

\begin{tabular}{|c|c|c|c|c|c|c|c|c|c|c|c|c|}
\hline & Mean & SD & 1. & 2. & 3. & 4. & 5. & 6. & 7. & 8. & 9. & 10. \\
\hline 1. Sex & 0.59 & 0.49 & - & & & & & & & & & \\
\hline 2. Age & 50.30 & 9.75 & -.01 & - & & & & & & & & \\
\hline 3. Place of birth & 0.91 & 0.28 & .03 & .04 & - & & & & & & & \\
\hline 4. Education & 4.68 & 1.75 & $.14 * * *$ & $-.21 * * *$ & -.02 & - & & & & & & \\
\hline $\begin{array}{l}\text { 5. Employment } \\
\text { period }\end{array}$ & 14.48 & 12.04 & $-.11 * *$ & $.51 * * *$ & .04 & $-.23 * * *$ & - & & & & & \\
\hline 6. Position & 0.14 & 0.34 & $-.09 * *$ & .01 & .03 & $.10^{* *}$ & -.03 & - & & & & \\
\hline 7. HADS & 0.54 & 0.40 & $.10 * *$ & $-.15 * * *$ & -.03 & .04 & $-.09 *$ & -.04 & - & & & \\
\hline 8. RIM & 5.39 & 1.13 & .05 & $.11 * *$ & $-.10 * *$ & -.03 & $.14 * * *$ & $.08^{*}$ & $-.31 * * *$ & - & & \\
\hline 9. Intervened & 0.13 & 0.33 & .05 & -.02 & .00 & -.04 & -.01 & .05 & $.10^{* *}$ & $-.13 * * *$ & - & \\
\hline $\begin{array}{l}\text { 10. Did not } \\
\text { intervene }\end{array}$ & 0.14 & 0.35 & -.01 & -.05 & -.02 & -.06 & -.06 & .04 & $.13 * * *$ & $-.13 * * *$ & $-.16^{* * *}$ & - \\
\hline $\begin{array}{l}\text { 11. New bullying } \\
\text { (T2) }\end{array}$ & 0.05 & 0.23 & .01 & $-.10^{* *}$ & $-.08 *$ & -.06 & -.06 & .02 & $-.12 * * *$ & $-.12 * * *$ & .04 & $.14 * * *$ \\
\hline
\end{tabular}

Note. Sex: men $=0$, women $=1$. Place of birth: foreign-born $=0$, Swedish-born $=1$. Education in 8 levels. Employment period at the same workplace. Position: not a managerial position $=0$, managerial position $=1$. HADS = Hospital Anxiety and Depression Scale (mean). RIM = Roles in the Organization (mean). Intervened, those who witnessed bullying at $\mathrm{T} 1$ and intervened $=1$, all others $=0$. Did not intervene, those who witnessed bullying at $\mathrm{T} 1$ and did not intervene $=1$, all others $=0$. New bullying $=$ new cases of bullying $(\mathrm{NAQ}-\mathrm{R} \geq 33)$ at follow-up. All cases of bullying at baseline were removed for all measures.

$* \mathrm{p}<.05 . * * \mathrm{p}<.01 . * * * \mathrm{p}<.001$.

Table 2 presents the crude odds ratios for all the study variables. With no controls added there was no increased risk for subsequent bullying if intervening, but a more than threefold risk for witnesses who did not intervene. Other significant risks regarding the control variables were younger people, being foreign-born, mental health problems, and an unclear and unordered organization. 


\section{Table 2}

Crude OR for all Study Variables, Logistic Regression Predicting Bullying (NAQ-R $\geq 33$ ) at Follow-up (All Bullied at Baseline were Excluded)

\begin{tabular}{llllll}
\hline & $\mathrm{b}$ & $\mathrm{SE}$ & $\mathrm{OR}$ & $95 \% \mathrm{CI}$ & \\
\hline Sex (male = base) & 0.05 & 0.32 & 1.05 & $(0.56-1.98)$ & $\mathrm{p}=.869$ \\
Age & -0.04 & 0.02 & 0.96 & $(0.93-0.99)$ & $\mathrm{p}=.004$ \\
Place of birth (Sweden = base) & 0.92 & 0.41 & 2.52 & $(1.12-5.66)$ & $\mathrm{p}=.026$ \\
Education & 0.04 & 0.09 & 1.04 & $(0.87-1.24)$ & $\mathrm{p}=.670$ \\
Period of employment & -0.02 & 0.02 & 0.98 & $(0.95-1.00)$ & $\mathrm{p}=.111$ \\
Managerial position (supervisor $=$ & -0.26 & 0.43 & 0.77 & $(0.33-1.77)$ & $\mathrm{p}=.535$ \\
base) & 1.02 & 0.33 & 2.78 & $(1.45-5.33)$ & $\mathrm{p}=.002$ \\
HADS (T1) & -0.40 & 0.12 & 0.67 & $(0.53-0.85)$ & $\mathrm{p}=.001$ \\
RIM (T1) & $\mathbf{0 . 4 8}$ & $\mathbf{0 . 4 1}$ & $\mathbf{1 . 6 0}$ & $\mathbf{( 0 . 7 2 - 3 . 5 6 )}$ & $\mathbf{p}=.247$ \\
$\begin{array}{l}\text { Intervened (T1), all others = base } \\
\text { Did not Intervene (T1), all others }=\end{array}$ & $\mathbf{1 . 2 9}$ & $\mathbf{0 . 3 4}$ & $\mathbf{3 . 6 2}$ & $\mathbf{( 1 . 8 7 - 7 . 0 3 )}$ & $\mathbf{p}<.001$ \\
base & & & & & \\
\hline
\end{tabular}

Note. HADS = Hospital Anxiety and Depression Scale (mean). RIM = Roles in the Organization (mean). Intervened: those who witnessed bullying at $\mathrm{T} 1$ and intervened $=1$, all others $=0$. Did not intervene: those who witnessed bullying at $\mathrm{T} 1$ and did not intervene $=1$, all others $=0$.

Table 3

Logistic Regression Predicting Bullying (NAQ-R $\geq 33)$ at Follow-up for Those who Witnessed Bullying at Baseline and Intervened (All Bullied at Baseline were Excluded)

\begin{tabular}{llllll}
\hline & $\mathrm{b}$ & $\mathrm{SE}$ & $\mathrm{OR}$ & $95 \% \mathrm{CI}$ & \\
\hline Sex (male = base) & 0.08 & 0.35 & 1.08 & $(0.55-2.15)$ & $\mathrm{p}=.819$ \\
Age & -0.04 & 0.02 & 0.96 & $(0.93-1.00)$ & $\mathrm{p}=.038$ \\
Place of birth (Sweden = base) & 1.10 & 0.44 & 3.00 & $(1.28-7.08)$ & $\mathrm{p}=.012$ \\
Education & -0.03 & 0.10 & 0.97 & $(0.80-1.17)$ & $\mathrm{p}=.733$ \\
Period of employment & -0.00 & 0.02 & 1.00 & $(0.96-1.04)$ & $\mathrm{p}=.946$ \\
Managerial position (supervisor $=$ & -0.47 & 0.45 & 0.63 & $(0.26-1.52)$ & $\mathrm{p}=.303$ \\
base) & 0.54 & 0.39 & 1.71 & $(0.80-3.65)$ & $\mathrm{p}=.165$ \\
HADS (T1) & -0.35 & 0.14 & 0.70 & $(0.53-0.92)$ & $\mathrm{p}=.012$ \\
RIM (T1) & $\mathbf{0 . 2 0}$ & $\mathbf{0 . 4 4}$ & $\mathbf{1 . 2 2}$ & $\mathbf{( 0 . 5 2 - 2 . 8 9 )}$ & $\mathbf{p}=. \mathbf{6 4 3}$ \\
Intervened (T1), all others = base & & & & &
\end{tabular}

Note. HADS = Hospital Anxiety and Depression Scale (mean). RIM = Roles in the Organization (mean). Intervened: those who witnessed bullying at $\mathrm{T} 1$, intervened $=1$, all others $=0$.

Controlling for sex, age, place of birth, education, period of employment, and managerial position, and adjusting for baseline mental health problems, and role clarity and order in the organization, Table 3 shows the risk of becoming bullied at follow-up if intervening when witnessing bullying at baseline. The same analysis was carried out for those who did not intervene (Table 4). The results showed no increased risk of being bullied at follow-up for those who witnessed bullying at baseline and intervened, OR $=1.22,95 \% \mathrm{CI}$ [0.52-2.89] compared to all others not bullied at baseline (research question 1). However, the risk was more than threefold if witnessing bullying and not intervening, OR $=3.34,95 \%$ CI [1.66-6.74] (research question 2). Based on the Cox \& Snell R Square and Nagelkerke pseudo R Square values, the predictors explained $3-10 \%$ of the variance in subsequent workplace bullying when analysing those who intervened. The regression model was supported by a significant chisquare test, $\chi^{2}(9)=26.11, p=.002$, and by a nonsignificant Hosmer and Lemeshow test, $\chi^{2}$ 
$(8)=7.29, p>.05$. For the second analysis, analysing those who did not intervene, based on the Cox \& Snell R Square and Nagelkerke pseudo R Square values, the predictors explained $5-13 \%$ of the variance in subsequent workplace bullying. The model was supported by a significant chi-square test, $\chi^{2}(9)=36.16, \mathrm{p}<.001$, and by a nonsignificant Hosmer and Lemeshow test, $\chi^{2}(8)=6.00, p>.05$. As can be seen in Tables 3 and 4 , the control variables age, place of birth, and clear roles were associated with bullying at follow-up. In line with previous research there was a decreased risk of bullying with age, an increased risk if foreignborn, and a decrease risk if there are clear roles at one's workplace.

\section{Table 4}

Logistic Regression Predicting Bullying (NAQ-R $\geq 33$ ) at Follow-up for Those who Witnessed Bullying at Baseline and did not Intervene (All Bullied at Baseline were Excluded)

\begin{tabular}{llllll}
\hline & $\mathrm{b}$ & $\mathrm{SE}$ & $\mathrm{OR}$ & $95 \% \mathrm{CI}$ & \\
\hline Sex (male = base) & 0.22 & 0.36 & 1.24 & $(0.62-2.50)$ & $\mathrm{p}=.538$ \\
Age & -0.04 & 0.02 & 0.96 & $(0.92-1.00)$ & $\mathrm{p}=.031$ \\
Place of birth (Sweden = base) & 1.15 & 0.44 & 3.16 & $(1.32-7.53)$ & $\mathrm{p}=.010$ \\
Education & -0.07 & 0.10 & 0.93 & $(0.77-1.13)$ & $\mathrm{p}=.464$ \\
Period of employment & 0.00 & 0.02 & 1.00 & $(0.96-1.04)$ & $\mathrm{p}=.994$ \\
Managerial position (supervisor $=$ & -0.50 & 0.45 & 0.60 & $(0.25-1.47)$ & $\mathrm{p}=.266$ \\
base) & 0.43 & 0.40 & 1.54 & $(0.70-3.40)$ & $\mathrm{p}=.284$ \\
HADS (T1) & -0.35 & 0.14 & 0.70 & $(0.53-0.94)$ & $\mathrm{p}=.016$ \\
RIM (T1) & $\mathbf{1 . 2 1}$ & $\mathbf{0 . 3 6}$ & $\mathbf{3 . 3 4}$ & $\mathbf{( 1 . 6 6 - 6 . 7 4 )}$ & $\mathbf{p}=. \mathbf{0 0 1}$ \\
Did not intervene (T1), all others $=$ & & & & &
\end{tabular}

Note. HADS $=$ Hospital Anxiety and Depression Scale (mean). RIM = Roles in the Organization (mean). Did not intervene: those who witnessed bullying at $\mathrm{T} 1$, did not intervene $=1$, all others $=0$.

\section{Discussion}

Based on a longitudinal probability survey of the Swedish working population, we investigated the risks associated with the actions that follow witnessing bullying at one's workplace - the risks if intervening, and the risks if remaining inactive. As bullying is an extreme stressor and a form of psychological violence at work, intervening in an ongoing bullying situation is potentially beneficial for the health and well-being of the victim (Nielsen et al., 2021). However, intervening may also increase the risk of becoming the next target, so hesitation and unwillingness to act may be understandable (Bjørkelo et al., 2011). Becoming a victim oneself is also something many witnesses believe is a likely consequence of intervening (Baez-Leon et al., 2016; D'Cruz \& Noronha, 2011). Contrasting these expectations, our results showed that there was no increased risk of becoming the next target if intervening (research question 1). Yet, if remaining inactive as a bystander to bullying the risk of becoming bullied oneself was more than threefold compared to all others not bullied at baseline (research question 2). This means that if one intervenes when witnessing bullying one is not only providing help and support to a victim, there is also a degree of self-preservation following the act.

The results from this study may be interpreted in light of three different theoretical models: (a) the work environment hypothesis (Leymann, 1996), (b) the notion of predatory bullying (Einarsen, 1999), and (c) the bystander effect (Latané \& Darley, 1970). The work environment hypothesis states that deficits in the work environment can lead to contradictory and unclear expectations increasing the risk of frustration, conflict, and aggression that could escalate into bullying (Salin \& Hoel, 2020). Intervening when witnessing bullying may contrib- 
ute to counteract the deficits that lay the ground for bullying to occur. That is, by intervening, the issue of bullying at the workplace becomes more visible to co-workers and managers, making it part of the agenda at work meetings, and therefore a possibility of reduction in the future. An important aspect of making it visible is that it can enhance the ethical infrastructure of the organization (Einarsen et al., 2017; Einarsen et al., 2019). An ethical infrastructure contains formal and informal systems that help define conduct and ethical behaviours at the workplace, and how not to treat each other. Einarsen et al. (2017) showed that both these systems interact and that an ethical infrastructure is related to successful handling of workplace bullying.

An important aspect of bullying and why it can continue is the power relation between the target and the bully. Predatory bullying means the target for some reason is singled out by a bully as a way to show power or exploiting a weakness in the target - sometimes based on a minority status or merely being an easy target of frustration and stress (Einarsen et al., 2020). If bullying is based on singling out an easy target, intervening to try to stop the bullying would probably not make the bully view the intervener as easy prey as the intervener dared to speak out or act against the behaviour of the bully. Also, if the bully sees that the target is not alone, the power balance may be changed to be more in favour of the target. In this case, it could be of importance how the bystander is categorized by the bully and by other bystanders (Glambek et al., 2020). Social categorization theory (Turner, 2010) may also shed light on the role of power relation. That is, if the intervener is viewed as part of the same social out-group as the target, intervening may be associated with future mistreatment all the same. More research is needed regarding the bystander role(s) and how one is categorized as a bystander.

In terms of the bystander effect (Latané \& Darley, 1970), intervening may also lead to other bystanders getting involved, as intervening may make an otherwise ambiguous situation clearer, and by this happening, evaluation of apprehension and pluralistic ignorance may be reduced (Fischer et al., 2011). Based on the model by Niven et al. (2020), the act of intervening may influence the cognitive appraisal in other witnesses changing the perception of the event. It can also change the attribution process of other witnesses-from a blaming the victim perspective to external causes (Hellemans et al., 2017). $\mathrm{Ng}$ et al. (2021) showed that the number of active constructive bystanders had a positive impact in the victim's work engagement, thus highlighting the importance of involving multiple active bystanders in a bullying situation.

The current study also gives an additional insight into a previous study based on the same sample that showed that not intervening when witnessing bullying was associated with later mental health problems (Nielsen et al., 2021). Mental health problems are known consequences of exposure to bullying behaviours (Nielsen \& Einarsen, 2012). The current study showed that the risk of becoming a new victim of bullying is more than threefold if not intervening. The increased mental health problems shown in the previous study could thereby be due to the fact that some of those who remained inactive when witnessing bullying actually became targets themselves later on and consequently experienced increased mental health problems.

Intervening as a witness probably has great value to the victim as the psychological violence may be stopped, at least at the moment. An important question is if it matters to the organization - what are the consequences of intervening beyond the individual level? Studies of the consequences of bystander behaviour when witnessing bullying are scarce. Björklund et al. (2019) interviewed managers focussing on factors that contribute to workplace bullying. One result was that passive bystanders increase the risk that ongoing bullying at the workplace will continue. However, the scarce evidence about the consequences of intervening as a witness highlights the importance of further research into this topic. When designing future studies, it 
may be beneficial to go beyond the bullying literature and seek inspiration from research on bystander behaviour in relation to other forms of mistreatment. For instance, emerging research has shown that the consequences of intervening with regard interpersonal violence are dependent upon factors such as type of helping behaviour, characteristics of the incident and the bystander's relationship to the victim and perpetrator (Banyard et al., 2019; Moschella \& Banyard, 2020).

\section{Limitations}

All measures were self-report measures susceptible to subjective factors such as social desirability and common method variance (Podsakoff \& Organ, 2016). A limitation of the study is also that we only have data on whether a witness intervened or remained inactive. The actual behaviours that the participants had in mind when they answered the question is not known in the current study. The indicator pertaining to bystander behaviours was developed specifically for this study and has therefore not been validated previously.

\section{Future Research Directions}

To better understand the specific consequences of intervening in situations of workplace bullying different bystander roles need to be studied in future research, for example the active, passive, destructive, and constructive bystander roles described by Paull et al. (2012). Future research should also investigate reasons for intervening and what organizational conditions that can facilitate or inhibit such behaviour. Although our data comes from a probability sample drawn from the whole Swedish working life, which strengthens the possibility of generalizing in a Swedish and possibly a Nordic context, it would be necessary to replicate the study in other parts of the world, in order to see whether the effects hold outside of Sweden. Further, it would be important to investigate the role of identification and categorization - is identification with the victim or the perpetrator important for the decision to act or remain inactive? Also, what role does categorization of the intervener by other bystanders and the perpetrator play when it comes to the consequences?

\section{Prevention and Policy Implications}

A practical implication of the findings is that organizations may benefit from facilitating report of misconduct, such as workplace bullying. That is, if employees have knowledge about available policies and routines for reporting bullying, while also knowing that the organization will protect their health and welfare if they chose to report, it is more likely that they will actively intervene when they witness bullying of others. Also, the role of fear of retaliation needs to be dealt with and conveying risks associated with inaction may help.

\section{Conclusions}

We have examined risks associated with witnessing workplace bullying. The results showed that intervening, that is, trying to help the victim, does not increase the risk of becoming the next target as opposed to popular belief. However, by remaining inactive as a bystander the risk of becoming the next target is threefold. By intervening there is a chance that the problem becomes more visible and thereby is dealt with, for example, as part of the formal and informal ethical infrastructure of the organization. Intervening in the often unclear and ambiguous situation in which bullying can occur may also help others see the need for action by reducing pluralistic ignorance and evaluation of apprehension. This study shows the importance of intervening when witnessing bullying - for the victim, but also for oneself. Also, taking action when someone needs help may also improve the organization by addressing the need to work with the ethical infrastructure. 


\section{References}

Baez-Leon, C., Moreno-Jimenez, B., Aguirre-Camacho, A., \& Olmos, R. (2016). Factors influencing intention to help and helping behaviour in witnesses of bullying in nursing settings. Nursing Inquiry, 23(4), 358-367. https://doi.org/10.1111/nin.12149

Banyard, V., Moschella, E., Grych, J., \& Jouriles, E. (2019). What happened next? New measures of consequences of bystander actions to prevent interpersonal violence. Psychology of Violence, 9(6), 664-674. https://doi.org/10.1037/vio0000229

Bjelland, I., Dahl, A. A., Haug, T. T., \& Neckelmann, D. (2002). The validity of the Hospital Anxiety and Depression Scale. Journal of Psychosomatic Research, 52(2), 69-77. https://doi.org/10.1016/s0022-3999(01)00296-3

Bjørkelo, B. (2013). Workplace bullying after whistleblowing: future research and implications. Journal of Managerial Psychology, 28(3), 306-323. https://doi.org/10.1108/02683941311321178

Bjørkelo, B., Einarsen, S., Nielsen, M. B., \& Matthiesen, S. B. (2011). Silence is golden? Characteristics and experiences of self-reported whistleblowers. European Journal of Work and Organizational Psychology, 20(2), 206-238. https://doi.org/10.1080/13594320903338884

Björklund, C., Hellman, T., Jensen, I., Åkerblom, C., \& Brämberg, E. B. (2019). Workplace Bullying as Experienced by Managers and How They Cope: A Qualitative Study of Swedish Managers. International Journal of Environmental Research and Public Health, 16(23). https://doi.org/10.3390/ijerph16234693

Chen, H., Cohen, P., \& Chen, S. (2010). How Big is a Big Odds Ratio? Interpreting the Magnitudes of Odds Ratios in Epidemiological Studies. Communications in Statistics - Simulation and Computation, 39(4), 860-864. https://doi.org/10.1080/03610911003650383

Cosco, T. D., Doyle, F., Ward, M., \& McGee, H. (2012). Latent structure of the Hospital Anxiety And Depression Scale: a 10-year systematic review. Journal of Psychosomatic Research, 72(3), 180-184. https://doi.org/10.1016/j.jpsychores.2011.06.008

Cropanzano, R., Goldman, B., \& Folger, R. (2003). Deontic justice: the role of moral principles in workplace fairness. Journal of Organizational Behavior, 24(8), 10191024. https://doi.org/10.1002/job.228

D'Cruz, P., \& Noronha, E. (2011). The limits to workplace friendship. Employee Relations, 33(3), 269-288. https://doi.org/10.1108/01425451111121777

Einarsen, K., Mykletun, R. J., Einarsen, S. V., Skogstad, A., \& Salin, D. (2017). Ethical Infrastructure and Successful Handling of Workplace Bullying. Nordic Journal of Working Life Studies, 7(1). https://doi.org/10.18291/njwls.v7i1.81398

Einarsen, K., Salin, D., Einarsen, S. V., Skogstad, A., \& Mykletun, R. J. (2019). Antecedents of ethical infrastructures against workplace bullying. Personnel Review, 48(3), 672690. https://doi.org/10.1108/pr-10-2017-0303

Einarsen, S. (1999). The nature and causes of bullying at work. International Journal of Manpower, 20(1/2), 16-27. https://doi.org/10.1108/01437729910268588

Einarsen, S., Hoel, H., \& Notelaers, G. (2009). Measuring exposure to bullying and harassment at work: Validity, factor structure and psychometric properties of the Negative Acts Questionnaire-Revised. Work \& Stress, 23(1), 24-44. https://doi.org/10.1080/02678370902815673

Einarsen, S., Hoel, H., Zapf, D., \& Cooper, C. L. (2020). The concept of bullying and harassment at work: The European tradition. In S. V. Einarsen, H. Hoel, D. Zapf, \& C. L. Cooper (Eds.), Bullying and harassment in the workplace. Theory, research and practice (3rd ed., pp. 3-53). CRC Press. 
Erdfelder, E., Faul, F., \& Buchner, A. (1996). GPOWER: A general power analysis program. Behavior Research Methods, Instruments, \& Computers, 28(1), 1-11. https://doi.org/10.3758/bf03203630

Fischer, P., Krueger, J. I., Greitemeyer, T., Vogrincic, C., Kastenmuller, A., Frey, D., Heene, M., Wicher, M., \& Kainbacher, M. (2011). The bystander-effect: a meta-analytic review on bystander intervention in dangerous and non-dangerous emergencies. Psychological Bulletin, 137(4), 517-537. https://doi.org/10.1037/a0023304

Glambek, M., Einarsen, S. V., \& Notelaers, G. (2020). Workplace bullying as predicted by non-prototypicality, group identification and norms: a self-categorisation perspective. Work \& Stress, 1-21. https://doi.org/10.1080/02678373.2020.1719554

Hellemans, C., Dal Cason, D., \& Casini, A. (2017). Bystander Helping Behavior in Response to Workplace Bullying. Swiss Journal of Psychology, 76(4), 135-144. https://doi.org/10.1024/1421-0185/a000200

Hoel, H., Cooper, C. L., \& Einarsen, S. V. (2020). Organizational effects of workplace bullying. In S. V. Einarsen, H. Hoel, D. Zapf, \& C. L. Cooper (Eds.), Bullying and harassment in the workplace. Theory, research and practice (3rd ed., pp. 209-234). CRC Press.

Latan, H., Chiappetta Jabbour, C. J., \& Lopes de Sousa Jabbour, A. B. (2019). To Blow or Not to Blow the Whistle: The Role of Rationalization in the Perceived Seriousness of Threats and Wrongdoing. Journal of Business Ethics, 169(3), 517-535. https://doi.org/10.1007/s10551-019-04287-5

Latané, B., \& Darley, J. M. (1970). The unresponsive bystander: Why doesn't he help? Prentice Hall.

Lewis, D., Giga, S., \& Hoel, H. (2011). Discrimination and bullying. In S. Einarsen, H. Hoel, D. Zapf, \& C. L. Cooper (Eds.), Bullying and harassment in the workplace (pp. 267281). CRC Press.

Leymann, H. (1996). The content and development of mobbing at work. European Journal of Work and Organizational Psychology, 5(2), 165-184. https://doi.org/10.1080/13594329608414853

Linstead, S. (2013). Organizational bystanding: whistleblowing, watching the work go by or aiding and abetting?M@n@gement,16(5).https://doi.org/10.3917/mana.165.0680

Lutgen-Sandvik, P., \& McDermott, V. (2011). Making Sense of Supervisory Bullying: Perceived Powerlessness, Empowered Possibilities. Southern Communication Journal, 76(4), 342-368. https://doi.org/10.1080/10417941003725307

Mikkelsen, E. G., Hansen, Å. M., Persson, R., Fosgrau Byrgesen, M., \& Hogh, A. (2020). Individual consequences of being exposed to workplace bullying. In S. V. Einarsen, H. Hoel, D. Zapf, \& C. L. Cooper (Eds.), Bullying and harassment in the workplace. Theory, research and practice (3rd ed., pp. 163-208). CRC Press.

Moschella, E. A., \& Banyard, V. L. (2020). Reactions to Actions: Exploring How Types of Bystander Action Are Linked to Positive and Negative Consequences. Journal of Primary Prevention, 41(6), 585-602. https://doi.org/10.1007/s10935-020-00618-9

Ng, K., Niven, K., \& Hoel, H. (2019). 'I could help, but . . .': A dynamic sensemaking model of workplace bullying bystanders. Human Relations. https://doi.org/10.1177/0018726719884617

Ng, K., Niven, K., \& Notelaers, G. (2021). Does bystander behavior make a difference? How passive and active bystanders in the group moderate the effects of bullying exposure. Journal of Occupational Health Psychology. https://doi.org/10.1037/ocp0000296

Nielsen, M. B., \& Einarsen, S. (2012). Outcomes of exposure to workplace bullying: A metaanalytic review. Work \& Stress, 26(4), 309-332. https://doi.org/10.1080/02678373.2012.734709 
Nielsen, M. B., Mageroy, N., Gjerstad, J., \& Einarsen, S. (2014). Workplace bullying and subsequent health problems. Tidsskrift for Den norske legeforening, 134(12-13), 1233-1238. https://doi.org/10.4045/tidsskr.13.0880

Nielsen, M. B., Rosander, M., Blomberg, S., \& Einarsen, S. V. (2021). Killing two birds with one stone: how intervening when witnessing bullying at the workplace may help both target and the acting observer. International Archives of Occupational and Environmental Health, 94(2), 261-273. https://doi.org/10.1007/s00420-020-01575-w

Niven, K., Ng, K., \& Hoel, H. (2020). The bystanders of workplace bullying. In S. V. Einarsen, H. Hoel, D. Zapf, \& C. L. Cooper (Eds.), Bullying and harassment in the workplace. Theory, research and practice (3rd ed., pp. 385-408). CRC Press.

Notelaers, G., \& Einarsen, S. (2013). The world turns at 33 and 45: Defining simple cutoff scores for the Negative Acts Questionnaire-Revised in a representative sample. European Journal of Work and Organizational Psychology, 22(6), 670-682. https://doi.org/10.1080/1359432x.2012.690558

O'Reilly, J., \& Aquino, K. (2011). A Model of Third Parties' Morally Motivated Responses to Mistreatment in Organizations. Academy of Management Review, 36(3), 526-543. https://doi.org/10.5465/amr.2011.61031810

Paull, M., Omari, M., \& Standen, P. (2012). When is a bystander not a bystander? A typology of the roles of bystanders in workplace bullying. Asia Pacific Journal of Human Resources, 50(3), 351-366. https://doi.org/10.1111/j.1744-7941.2012.00027.x

Podsakoff, P. M., \& Organ, D. W. (2016). Self-Reports in Organizational Research: Problems and Prospects. Journal of Management, 12(4), 531-544. https://doi.org/10.1177/014920638601200408

Rosander, M. (2021). Mental Health Problems as a Risk Factor for Workplace Bullying: The Protective Effect of a Well-Functioning Organization. Annals of Work Exposures and Health. https://doi.org/10.1093/annweh/wxab040

Rosander, M., \& Blomberg, S. (2018). The WHOLE picture: Measurement of psychosocial work environment. Linköping University Electronic Press.

Rosander, M., \& Blomberg, S. (2019). Levels of workplace bullying and escalation - a new conceptual model based on cut-off scores, frequency and self-labelled victimization. European Journal of Work and Organizational Psychology, 28(6), 769-783. https://doi.org/10.1080/1359432x.2019.1642874

Rosander, M., \& Blomberg, S. (2021). Workplace bullying of immigrants working in Sweden. The International Journal of Human Resource Management, 1-25. https://doi.org/10.1080/09585192.2021.1891113

Salin, D. (2001). Prevalence and forms of bullying among business professionals: A comparison of two different strategies for measuring bullying. European Journal of Work and Organizational Psychology, 10(4), 425-441. https://doi.org/10.1080/13594320143000771

Salin, D., \& Hoel, H. (2020). Organizational risk factors of workplace bullying. In S. Einarsen, H. Hoel, D. Zapf, \& C. L. Cooper (Eds.), Bullying and Harassment in the Workplace. Theory, Research, and Practice (3rd ed., pp. 305-329). CRC Press.

Salin, D., \& Notelaers, G. (2020). The effects of workplace bullying on witnesses: violation of the psychological contract as an explanatory mechanism? The International Journal of Human Resource Management, 31(18), 2319-2339. https://doi.org/10.1080/09585192.2018.1443964

Turner, J. C. (2010). Social categorization and the self-concept: A social cognitive theory of group behavior. In T. Postmes \& N. R. Branscombe (Eds.), Rediscovering social identity (pp. 243-272). Psychology Press. 
Zapf, D., Escartín, J., Scheppa-Lahyani, M., Einarsen, S. V., Hoel, H., \& Vartia, M. (2020). Empirical findings on prevalence and risk groups of bullying in the workplace. In S. V. Einarsen, H. Hoel, D. Zapf, \& C. L. Cooper (Eds.), Bullying and harassment in the workplace. Theory, research and practice (3rd ed., pp. 105-162). CRC Press.

Zhang, Y., Hedo, R., Rivera, A., Rull, R., Richardson, S., \& Tu, X. M. (2019). Post hoc power analysis: is it an informative and meaningful analysis? General Psychiatry, 32(4), e100069. https://doi.org/10.1136/gpsych-2019-100069

Zigmond, A. S., \& Snaith, R. P. (1983). The hospital anxiety and depression scale. Acta Psychiatrica Scandinavica, 67(6), 361-370. https://doi.org/10.1111/j.16000447.1983.tb09716.x 